\title{
Role of Nitrous Oxide in Ambulatory Anaesthesia
}

\author{
Sarah Billingham • Ian Smith
}

Published online: 31 July 2014

(C) Springer Science + Business Media New York 2014

\begin{abstract}
As the oldest anaesthetic still in routine use, the continued role of nitrous oxide is frequently questioned. There are a few well-defined situations in which nitrous oxide is contraindicated or undesirable; it is environmentally damaging and known to be toxic with prolonged exposure. However, evidence of serious harm is relatively lacking and mostly relates to prolonged and major surgery. In the ambulatory setting, the adverse effects of nitrous oxide are more limited and of minimal clinical relevance. Furthermore, there are numerous benefits which are not easily replicated by possible alternatives. Specifically, nitrous oxide improves the quality, speed and safety of induction of anaesthesia, enhances the quality of the maintenance phase, facilitates faster recovery and may reduce the occurrence of chronic postoperative pain, all with minimal adverse effects and while also reducing overall costs. Except in very specific circumstances, the minimal disadvantages and considerable benefits suggest that nitrous oxide still retains a valuable place in modern ambulatory anaesthesia.
\end{abstract}

Keywords Ambulatory anaesthesia - Nitrous oxide . Postoperative nausea and vomiting - Recovery $\cdot$ Adverse perioperative outcomes

\section{Introduction}

Nitrous oxide heralded the birth of anaesthesia in 1844 [1] and remains in use today. The intervening 170 years have seen the introduction and subsequent withdrawal of many

S. Billingham $\cdot$ I. Smith $(\bowtie)$

University Hospital of North Staffordshire, Newcastle Road,

Stoke-on-Trent, Staffordshire ST4 6QG, UK

e-mail: damsmith@btinternet.com other anaesthetic agents, and none of those currently in use have been available for even half of that time. Nitrous oxide, the "ageing gentleman" of anaesthesia [2], has many advantages and also some disadvantages. The latter, however, are well known and can generally be prevented by avoiding nitrous oxide in various clearly defined circumstances. Nevertheless, while some continue to praise the benefits of nitrous oxide [3], there are regular calls for its use to be abandoned $[4,5]$. Arguments for this include concerns about toxicity and possibly increased morbidity and mortality, adverse environmental effects and the lack of sufficient benefits to retain its use.

The use of nitrous oxide is undoubtedly declining [6•], although this seems to be because other agents are increasingly seen as "better", rather than because of specific concerns. After such a long time in use, it is perhaps surprising that there remains great uncertainty about whether nitrous oxide is generally harmful [7,8], or whether it even reduces mortality [3]. This review will consider the specific advantages and possible disadvantages of nitrous oxide in ambulatory anaesthesia.

\section{Toxicity of Nitrous Oxide}

It has been know for almost 60 years that prolonged administration of nitrous oxide causes bone marrow depression through inhibition of methionine synthesis [2]. For this reason, nitrous oxide is not used for intensive care sedation and is avoided during prolonged procedures, but this is irrelevant to ambulatory anaesthesia where the duration of surgery is typically $1-2 \mathrm{~h}$. Bone marrow depression after only a few hours exposure has been reported, but only in critically-ill patients [4] and is probably still of no consequence in ambulatory anaesthesia. 
As methionine synthase catalyses the final step in the regeneration of methionine from homocysteine, its inactivation results in dose-dependent increases in homocysteine. Chronically increased homocysteine levels are an independent risk factor for coronary artery and cerebrovascular disease as a result of impaired endothelial function $[7,9],\left[10^{\bullet}\right]$, providing a possible mechanism by which nitrous oxide might be toxic. Support has recently been lent to this view by the finding of an increased risk of myocardial infarction, but not of death or stroke, in a late follow-up of an earlier randomised study (the ENIGMA trial) [10•]. These results may have limited relevance to ambulatory surgery, however, as the trial evaluated nitrous oxide in patients having major non-cardiac surgery lasting more than $2 \mathrm{~h}$. Although the trial was randomised, the inspired oxygen concentration differed markedly between the groups, being $30 \%$ in patients receiving nitrous oxide and $80 \%$ in those whom avoided it [10॰], another possible explanation for the results observed. In addition, the trial has been criticised [9] for having relatively low power, especially when taking into consideration the number of patients lost to follow-up.

Rather more reassuringly, retrospective analysis of several other major clinical trials has failed to detect an adverse effect of nitrous oxide [11•], [12•], [13••], [14]. In particular, nitrous oxide was associated with no increase in stroke, myocardial infarction or death in the GALA trial in patients undergoing carotid surgery $\left[11^{\bullet}\right]$ and no increase in myocardial infarction or death in the POISE trial of betablockers [12•]. Nitrous oxide use also had no detrimental effect on functional or neurologic status three months after cerebral aneurysm surgery with temporary cerebral artery occlusion [14]. Nitrous oxide use had no effect on the incidence of postoperative delirium or cognitive dysfunction in elderly patients [15]. Even more reassuringly, one recent retrospective study showed a positive benefit of nitrous oxide which was associated with decreased odds of mortality within 30 days of non-cardiac surgery [13*•]. The use of nitrous oxide also did not increase the chances of recurrence after cancer surgery [16]. A recent systematic review on the possible hazards of nitrous oxide found insufficient trials with low risk of bias to construct a metaanalysis for many of the relevant outcomes and concluded that we do not have robust evidence on whether or not nitrous oxide affects mortality or cardiovascular complications [17].

In order to provide more definitive evidence on possible long-term harm, a large international randomised controlled trial (ENIGMA-II) has been conducted to evaluate the effect of nitrous oxide on a composite outcome measure of death and cardiovascular complications within 30 days of surgery. Although the results have not yet been formally published, the outcomes of the 7,112 enrolled patients have been presented at the 2014 combined RACS and ANZCA annual scientific congress in Singapore. Death or cardiovascular complications (including non-fatal myocardial infarction, stroke, pulmonary embolism or cardiac arrest) were not significantly increased, occurring in $8.1 \%$ of patients receiving nitrous oxide and $8.4 \%$ of those in whom it was omitted. Perhaps of more relevance to ambulatory surgery, nitrous oxide also did not increase the incidence of surgical wound infections, a finding which has been confirmed by another randomised controlled trial [18].

\section{Expansion of Air-Filled Spaces}

It is well known that nitrous oxide diffuses into air-filled spaces faster than nitrogen can diffuse out, thereby causing expansion or pressure increases. In some cases, there are absolute contraindications to the use of nitrous oxide, such as the presence of intracranial air, although this scenario is now increasingly uncommon. Less rare is a patient who has had eye surgery involving the placement of an intra-ocular gas bubble. These gases can take up to 3 months to reabsorb, and following recent surgery, diffusion of nitrous oxide can result in significant pressure changes resulting in permanent blindness [19]. Nitrous oxide can also diffuse into the air-filled cuffs of airway devices, resulting in an increase in pressure. For example, in adults managed with the ProSeal laryngeal mask airway (pLMA), nitrous oxide was able to diffuse in rapidly causing pressure increases within ten minutes, [20] although without increasing airway related complications. In contrast, when the size 2 pLMA was used in young children, the increase in cuff pressure caused by nitrous oxide was even greater and did result in a higher incidence of throat soreness [21]. However, these well-recognised complications can be readily avoided by regularly monitoring cuff pressures and adjusting as necessary, especially in more vulnerable patients.

Nitrous oxide can also diffuse into bowel, causing distension. In patients undergoing colonic resections lasting at least $3 \mathrm{~h}, 23 \%$ of patients receiving nitrous oxide had moderate to severe bowel distension which impaired surgery to some degree, compared to only $9 \%$ in those receiving air as a carrier gas [22]. The degree of distension caused by nitrous oxide appears to be directly related to the duration of surgery, however [23], and may therefore be of limited relevance to ambulatory surgery. For example, during laparoscopic cholecystectomy lasting 70-80 min, blinded surgeons rated intraoperative conditions equally and could not tell whether or not nitrous oxide was being used [24]. Similarly, nitrous oxide caused no significant bowel distension during $90 \mathrm{~min}$ of laparoscopic bariatric 
surgery [25]. Surgeons requested that nitrous oxide be discontinued to improve surgical conditions in three patients within these two studies [24, 25], but in only one case, was nitrous oxide actually being used. Even in longer surgery where bowel distension seems to be more prevalent, there is little evidence that nitrous oxide impairs postoperative bowel function or delays discharge [23].

\section{Postoperative Nausea and Vomiting}

Nitrous oxide is recognised to increase postoperative nausea and vomiting (PONV), and several mechanisms have been implicated, including actions on dopamine and opioid receptors, middle ear pressure changes and bowel distension [26•]. There is some evidence that nitrous oxide may increase PONV in a dose-dependent fashion [27]. The same appears to be true for volatile anaesthetics [26•], so substituting nitrous oxide for a higher delivered volatile anaesthetic concentration may be counterproductive as far as reducing PONV is concerned. This will also be the case if the intraoperative analgesic effect of nitrous oxide is replaced with opioid analgesia, another potent cause of PONV.

While PONV is an outcome which is particularly undesirable in ambulatory surgery [28], it appears that elimination of nitrous oxide results in only a relatively modest reduction in this important adverse event. One early meta-analysis of 24 trials found that omission of nitrous oxide was more effective in reducing the incidence of early and late vomiting than on early and late nausea [29]. The effect was relatively weak, however, with numbers needed to treat (NNT) for these four endpoints of 11.8, 13.8, 30, and 36.9, respectively. Omitting nitrous oxide did not improve complete control of PONV and did not improve outcome at all when the baseline incidence of vomiting was low [29]. A more recent meta-analysis of 33 clinical trials confirmed that omission of nitrous oxide reduced PONV from an overall incidence of 33-27\% [30]. The observed increase in PONV associated with nitrous oxide was greater in women than men but was almost completely avoided when propofol was used as the maintenance anaesthetic. With a NNT to prevent PONV of 17, the authors concluded that avoiding nitrous oxide does reduce the risk of PONV, "especially in women, but the overall impact is modest" [30]. It has recently been shown that the occurrence of PONV is linked to duration of exposure to nitrous oxide. The NNT to prevent PONV was as high as 128 for procedures lasting an hour or less and 23 for surgery of $1-2 \mathrm{~h}$ duration [31••], leading the authors to conclude that the effect of nitrous oxide on PONV "should not be seen as an impediment to its use in minor or ambulatory surgery". To put these values in context, a typical NNT to prevent PONV with an antiemetic such as ondansetron is about 5 [32].

Of some concern was that the earlier meta-analysis reported that the risk of intraoperative awareness was increased from omission of nitrous oxide to a comparable degree (number needed to harm 46.2) to any reduction in PONV [29]. This suggestion has been refuted by other observational studies [33] and was not confirmed by the more recent meta-analysis [30].

\section{Environmental Concerns}

Nitrous oxide contributes to depletion of the ozone layer and also traps thermal radiation escaping from the Earth, contributing to the "greenhouse" effect, with a warming potential approximately 300 times that of carbon dioxide [34]. Total volumes released are lower, however, and nitrous oxide contributes about $6 \%$ of the total greenhouse effect [34]. The majority of nitrous oxide arises from natural sources in the oceans and soil, with a further contribution from nitrogenous fertilisers, cattle and the burning of fossil fuels [34, 35]. Consequently, it has been estimated that anaesthetic use of nitrous oxide contributes no more than $3 \%$ of the total amount reaching the atmosphere from the USA [34] and probably less than $1 \%$ worldwide [35]. Its elimination from anaesthetic practice would currently have a negligible effect on the global environment.

Escape of waste nitrous oxide may also raise levels within the local environment. In the past, there were concerns about an apparent increase in spontaneous abortion rates in operating room staff chronically exposed to nitrous oxide [36]. The evidence was never totally compelling and could have been confounded by occupational stress and reporting bias [36], but the advent of scavenging virtually eliminated any problem there may have been. Scavenging is only effective while the patient is attached to a breathing circuit, so exhaled nitrous oxide may still be excreted into the air in the recovery room. However, careful monitoring showed that staff in the recovery room are exposed to very low amounts of nitrous oxide, with typical time weighted average concentrations of 1-4 ppm [37]. This is well below both the UK recommended $8 \mathrm{~h}$ time-weighted exposure maximum of $100 \mathrm{ppm} \mathrm{[38]} \mathrm{and} \mathrm{the} \mathrm{more} \mathrm{stringent} \mathrm{US}$ NIOSH limit of $25 \mathrm{ppm}$ [39], and therefore very unlikely to cause any adverse health effects, even among pregnant employees.

\section{Possible Benefits of Nitrous Oxide}

With the exception of a few very specific circumstances, the use of nitrous oxide during ambulatory anaesthesia has 
minimal impact on PONV or other important adverse outcomes. However, there may also be specific benefits resulting from its use. In particular, nitrous oxide is both an analgesic and a weak anaesthetic and should supplement other anaesthetics during the induction and maintenance phases, thereby reducing the dose required and possibly improving intraoperative conditions. The use of nitrous oxide has also been shown to reduce the incidence of chronic pain by more than half following major surgery, with $5.6 \%$ of patients receiving nitrous oxide experiencing severe chronic pain compared to $12.9 \%$ when nitrous oxide was avoided [40॰].

\section{Benefits During Induction}

Inhalation induction of anaesthesia is commonly performed in children and supplementing an $8 \%$ sevoflurane vital capacity induction with nitrous oxide shortened the induction interval and significantly reduced excitatory movements [41••]. Inhalation induction with sevoflurane also conveys some benefits for ambulatory surgical patients [42]. Vital capacity induction was $14 \%$ faster in the presence of $66 \%$ nitrous oxide, which also produced a smoother induction with fewer adverse airway events and a higher incidence of first time successful insertion of the laryngeal mask (LMA) [43]. The authors commented that the addition of nitrous oxide made induction of anaesthesia with sevoflurane safer, because no LMAs had to be reinserted in this group, the incidence of adverse airway events was less, and the excitatory phase was rapidly passed through, rendering induction "very smooth" [43]. Similarly, a Japanese study found that the addition of nitrous oxide not only hastened loss of consciousness but also improved cardiovascular stability during induction of anaesthesia with sevoflurane in adults [44].

Induction of anaesthesia with propofol is more common in adults, but breathing $66 \%$ nitrous oxide for one minute reduced the time from subsequent propofol administration until loss of consciousness by $41 \%$, while reducing the propofol dose by $44 \%$ [45]. Inhalation of nitrous oxide before induction of anaesthesia can also be used to reduce the distress of intravenous cannulation in children and young adults [46].

The improvements in inhalation induction facilitated by nitrous oxide are usually thought to result from the second gas effect during its uptake. Uncertainty about the actual rate of early uptake of nitrous oxide by pulmonary blood has fuelled controversy over the clinical significance of this effect, with some authors disputing that it exists at all [47, 48], or questioning that it is related to the uptake of large volumes of nitrous oxide [49]. When alveolar-capillary uptake of nitrous oxide and sevoflurane were directly measured using the reverse Fick method, the peak rate of uptake of nitrous oxide by pulmonary blood was found to be considerably greater than previously suggested, confirming a powerful second gas effect [50]. It has also been discovered that patients receiving nitrous oxide have a consistently higher arterial oxygen tension than those receiving an identical inspired oxygen concentration in nitrogen [51], consistent with persisting concentrating and second gas effects. This improved arterial oxygenation should provide a greater margin of safety, especially in frail and elderly patients undergoing ambulatory anaesthesia.

\section{Benefits During Maintenance}

Nitrous oxide results in improved intraoperative conditions when anaesthesia is maintained with either intravenous or inhalation agents. Compared to an infusion of alfentanil, $67 \%$ nitrous oxide halved intraoperative movement from 60 to $30 \%$ when used to supplement a target-controlled infusion of propofol [52]. Omitting nitrous oxide necessitated a $42 \%$ increase in the propofol infusion rate to maintain adequate anaesthesia but still resulted in an increase in intraoperative movement from 12 to $40 \%$ and failed to significantly reduce PONV [53]. Other workers have confirmed an increase in propofol requirements but failed to demonstrate any detriment from the omission of nitrous oxide in terms of quality or speed of recovery [54]. Nitrous oxide reduced the target propofol concentration necessary to prevent patient movement by almost $20 \%$ during oocyte retrieval for in vireo fertilisation [55]. When used with inhaled agents, nitrous oxide reduced the need for propofol boluses to supplement enflurane anaesthesia [56]. The reduction in inspired isoflurane concentration was achieved by $50 \%$ nitrous oxide also reduced the depression of arterial blood pressure and cardiac output was caused by isoflurane delivered alone to older adult patients [57]. Nitrous oxide decreased the use of sevoflurane by $60 \%$ and the hourly anaesthetic costs by $41 \%$, while resulting in a faster emergence from anaesthesia without adverse effects on later recovery or PONV [58].

Nitrous oxide has more complex EEG effects than the cortical depression produced by most anaesthetic agents and selective frontal recording combined with artefact filtering may miss many of these changes, effectively rendering several "depth of anaesthesia" monitors blind to nitrous oxide [59]. In the presence of clinically apparent sedation or even unconsciousness from nitrous oxide, there was no change in the recorded values of bispectral index [60], entropy [61] or cerebral state index [62]. Consequently, when bispectral index was used to guide titration of propofol-remifentanil anaesthesia, the addition of nitrous oxide appeared to have no anaesthetic sparing effect [63]. Although bispectral index values were unchanged, nitrous oxide did have a clinically relevant 
effect, as the incidence of intraoperative movement and the requirement for antihypertensive medications were more than halved [63]. The additional, but unmeasured, hypnotic effect of nitrous oxide should also offer additional protection against awareness when depth of anaesthesia monitors are used.

\section{Benefits During Recovery}

The very low solubility of nitrous oxide ensures that it is rapidly eliminated, so recovery is faster when it is used in conjunction with another anaesthetic agent to maintain anaesthesia than when the same agent is used alone at higher concentrations. When used to supplement propofol, nitrous oxide typically reduces the time until awakening and orientation by about 16-24\% [52, 64]. In conjunction with inhalation anaesthetics, the effect of nitrous oxide on recovery appears even greater. This may be because the second gas effect also occurs at the end of anaesthesia, when the rapid elimination of nitrous oxide produces a clinically significant acceleration in the reduction in the concentration of any accompanying volatile anaesthetic [65••]. Clinically, the addition of nitrous oxide reduced the time to awakening and orientation by about $40 \%$ [58].

The second gas effect should also contribute to diffusion hypoxia, as rapid elimination of nitrous oxide from the lungs dilutes alveolar oxygen [65••]. This is a relatively mild and transient phenomenon, in healthy patients at least, with abrupt discontinuation of nitrous oxide resulting in a decrease of only about $4 \%$ in pulse oximetry readings when air breathing [66]. The decrease lasted no more than five minutes and was prevented by a short period of highflow oxygen administration [66], as would be typical at the end of most anaesthetics. If oxygen is delivered at the end of anaesthesia, most patients do not require routine oxygen supplementation once they reach the recovery room, unless they have significant cardio-pulmonary disease [67].

\section{Alternatives to Nitrous Oxide}

Nitrous oxide fulfils several roles, serving as a carrier gas to dilute oxygen, an analgesic and also as a supplement to the primary anaesthetic agent. The carrier role is readily replaced with air, but the anaesthetic and analgesic effects are less easily substituted. Opioid supplementation or increased delivery of other anaesthetic agents (especially propofol) appears to be less effective in preventing intraoperative movement [52, 53] or awareness [29]. Because of the rapid elimination of nitrous oxide, increasing the primary anaesthetic concentration generally tends to delay recovery, [52, 58, 64] although some have found no apparent detriment to simply omitting nitrous oxide [54].
When it is suggested that nitrous oxide be abandoned [4], alternatives to be considered typically include remifentanil and xenon. This opioid analgesic and general anaesthetic, respectively, are both rapidly acting with a short duration of action and therefore approximate at least the kinetics of nitrous oxide.

\section{Remifentanil as a Nitrous Oxide Replacement}

The rapid elimination and analgesic properties of remifentanil make it the most obvious choice for a possible alternative to nitrous oxide. Perhaps surprisingly for an agent often suggested to be an optimal alternative, so far only one published study has compared remifentanil with nitrous oxide as anaesthetic supplements in ambulatory anaesthesia [68]. In this comparison, patients undergoing ambulatory orthopaedic surgery received desflurane and a $0.75 \mu \mathrm{g} / \mathrm{kg} / \mathrm{h}$ infusion of fentanyl which was supplemented with either $66 \%$ nitrous oxide or an infusion of remifentanil designed to achieve a comparable MAC-reducing plasma concentration of $2 \mathrm{ng} / \mathrm{ml}$. Awakening was equally rapid in both groups, although remifentanil was associated with a 2 min reduction in the time to orientation (median time reduced from 8.0 to $6.0 \mathrm{~min}$ ). All other recovery parameters, including later recovery, discharge time, pain and PONV, as well as patient satisfaction, were similar between the groups [68].

As a nitrous oxide replacement, remifentanil is not without its problems. It is substantially more expensive and more complex to administer. It is a significant respiratory depressant, making it particularly difficult to use if spontaneous ventilation is desired [69]. Although LMAs were used in the one published comparative study, controlled ventilation was used in both groups [68], even though spontaneous ventilation might be more common in this situation. Remifentanil is also a potent cause of PONV, despite its short duration of effect. Compared to the use of esmolol to maintain haemodynamic stability, the use of remifentanil significantly increased PONV from 4 to $35 \%$ [70].

There is also some evidence that remifentanil may induce acute opioid tolerance and hyperalgesia [71, 72], which may compromise subsequent pain relief. This acute tolerance is reported to be quite profound and to develop very rapidly, certainly within $2 \mathrm{~h}$ [72]. Others have disputed the phenomenon, finding no difference in pain scores or morphine consumption when remifentanil was infused in place of nitrous oxide during major colorectal surgery [73]. Postoperative pain scores were also comparable when remifentanil or nitrous oxide was used during ambulatory orthopaedic surgery [68]. However, when used together, nitrous oxide has been shown to reduce opioid induced hyperalgesia resulting from a remifentanil infusion [74•]. 
Xenon as a Nitrous Oxide Replacement

Like nitrous oxide, xenon has no action at the $\mathrm{GABA}_{\mathrm{A}}$ receptor and probably exerts most of its effects through antagonism of the NMDA receptor [75]. With extremely low blood-gas solubility of only 0.115 , xenon should match or exceed the kinetics of nitrous oxide, while its MAC value of about $70 \%$ would allow it to be used as a sole anaesthetic agent, allowing more rapid emergence than that observed after nitrous oxide combined with either isoflurane or sevoflurane [76].

As a rare constituent of the atmosphere, elimination of waste xenon would have no adverse environmental consequences. However, its production by fractional distillation of air consumes enormous amounts of energy, significantly more than is required for nitrous oxide production [34], rendering it rather less "environmentally friendly". The main limitation of xenon is its rarity and hence its cost, estimated as 2,000 times that of nitrous oxide [77]. As such, xenon is likely to be used only where it conveys significant benefit from its cardiovascular stability and ability to provide neuroprotection, for example, in high-risk cardiac surgery patients [75].

\section{Conclusions}

While nitrous oxide has some recognised adverse effects, these are well circumscribed and can easily be avoided or managed. The anaesthetic contribution to nitrous oxide reaching the upper atmosphere, and hence its environment effect, is negligible, and there has been no convincing evidence of harm to operating theatre or recovery room personnel since the routine use of waste gas scavenging. There is concern that nitrous oxide may increase adverse perioperative outcomes, perhaps by increasing homocysteine levels, but the evidence is contradictory and in any case confined to major inpatient surgery.

In ambulatory practice, nitrous oxide improves the quality and, by reducing adverse airway events, excitement and unanticipated movement and improving oxygenation, the safety of induction and maintenance of anaesthesia. Its use facilitates faster recovery and has only a minimal effect on PONV. Somewhat unusually, these benefits of nitrous oxide are accompanied by an overall reduction in costs.

Potential alternatives to nitrous oxide exist, but none can be considered a direct replacement for all of its properties. The use of these alternatives is more complex, considerably more costly and often less effective than nitrous oxide. Furthermore, the effects on long-term outcome of remifentanil and xenon are relatively unknown at present, in contrast to nitrous oxide which currently has a track record of 170 years and is still going strong. Nitrous oxide remains a valuable agent in ambulatory anaesthesia.

\section{Compliance with Ethics Guidelines}

Conflict of Interest Sarah Billingham and Ian Smith declare that they have no conflict of interest.

Human and Animal Rights and Informed Consent This article does not contain any studies with human or animal subjects performed by any of the authors.

\section{References}

Papers of particular interest, published recently, have been highlighted as:

- Of importance

-. Of major importance

1. Laird WRE. 'The Yankee Dodge': some new observations on the discovery of anaesthesia. Br Dent J. 1990;169(7):217-9.

2. Stenqvist O, Husum B, Dale O. Nitrous oxide: an ageing gentleman (Editorial). Acta Anaesthesiol Scand. 2001;45(2):135-7.

3. Hogan K, Myles PS. This wonder-working gas (Editorial). Anesth Analg. 2013;116(5):955-8.

4. Shaw ADS, Morgan M. Nitrous oxide: time to stop laughing? (Editorial). Anaesthesia. 1998;53(3):213-5.

5. Vetter TR, McGwin G Jr. Comparing apples to oranges: just say no to $\mathrm{N}_{2} \mathrm{O}$ ? (Editorial). Anesth Analg. 2013;116(5):959-61.

6. - Husum B, Stenqvist O, Alahuhta S et al. Current use of nitrous oxide in public hospitals in Scandinavian countries. Acta Anaesthesiol Scand 2013;57(9):1131-7. The use of nitrous oxide has decreased across Scandinavia, but with marked differences between individual countries. The main reason for this decline is predominantly because anaesthetists prefer other agents. However, the differences between the five countries shows that this can not be justified on published evidence alone.

7. Myles PS. Nitrous oxide: deep in the zone of uncertainty (Editorial). Anesthesiology. 2013;119(1):1-3.

8. Nagele P. Notorious oxide (Editorial). Anesthesiology. 2012;117(1): 3-5.

9. Beattie WS, Badner NH. The enigma of ENIGMA-I (Editorial). Anesth Analg. 2011;112(2):255-7.

10. - Leslie K, Myles PS, Chan MTV et al. Nitrous oxide and longterm morbidity and mortality in the ENIGMA trial. Anesth Analg 2011;112(2):387-93. The authors conducted a long-term (median 3.5 [0-5.7] years follow up of a previous trial of 2,050 patients randomised to receive $70 \%$ nitrous oxide with $30 \%$ oxygen or $80 \%$ oxygen with nitrogen during noncardiac surgery lasting more than 2 hours. Nitrous oxide was associated with increased long-term risk of myocardial infarction, but not of death or stroke. The study has been extensively criticised because of incomplete follow-up and the widely disparate inspired oxygen concentrations between the groups.

11. - Sanders RD, Graham C, Lewis SC et al. Nitrous oxide exposure does not seem to be associated with increased mortality, stroke, and myocardial infarction: a non-randomized subgroup analysis of the General Anaesthesia compared with Local Anaesthesia for carotid surgery (GALA) trial. Br J Anaesth 2012;109(3):361-7. The authors conducted a post hoc analysis of the GALA trial for 
carotid surgery, in which $42 \%$ of the 1,615 patients in whom the anaesthetic technique was known received nitrous oxide. Nitrous oxide was not associated with any clinically meaningful increased risk of death, stroke, or myocardial infarction within 30 days of carotid surgery.

12. - Leslie K, Myles P, Devereaux PJ et al. Nitrous oxide and serious morbidity and mortality in the POISE trial. Anesth Analg 2013;116(5):1034-40. The authors conducted a post hoc analysis of the POISE trial of perioperative beta-blockade, in which $29 \%$ of patients received nitrous oxide. Nitrous oxide had no signifcant effect on the risk of clinically significant hypotension, myocardial infarction, cardiac arrest, stroke or cardiovascular death within 30 days.

13. • Turan A, Mascha EJ, You J et al. The association between nitrous oxide and postoperative mortality and morbidity after noncardiac surgery. Anesth Analg 2013;116(5):1026-33. In this retrospective study, 10,755 patients who received nitrous oxide were propensity score-matched with another 10,755 patients in whom nitrous oxide was avoided. Intraoperative use of nitrous oxide was associated with a decreased odds ratio of 30-day mortality of 0.67 (CI 0.46-0.97; $p=0.02$ ) and an estimated decreased odds ratio of $0.83(0.74-0.92 ; p<0.001)$ of experiencing major in-hospital morbidity and mortality. The authors concluded that their results did not support eliminating nitrous oxide from anaesthetic practice.

14. Pasternak JJ, McGregor DG, Lanier WL, et al. Effect of nitrous oxide use on long-term neurologic and neuropsychological outcome in patients who received temporary proximal artery occlusion during cerebral aneurysm clipping surgery. Anesthesiology. 2009;110(3):563-73.

15. Leung JM, Sands LP, Vaurio LE, Wang Y. Nitrous oxide does not change the incidence of postoperative delirium or cognitive decline in elderly surgical patients. Br J Anaesth. 2006;96(6): 754-60

16. Fleischmann E, Marschalek C, Schlemitz K, et al. Nitrous oxide may not increase the risk of cancer recurrence after colorectal surgery: a follow-up of a randomized controlled trial. BMC Anesthesiol. 2009;9:1.

17. Imberger $\mathrm{G}$, Orr $\mathrm{A}$, Thorlund $\mathrm{K}$, et al. Does anaesthesia with nitrous oxide affect mortality or cardiovascular morbidity? A systematic review with meta-analysis and trial sequential analysis. Br J Anaesth. 2014;112(3):410-26.

18. Fleischmann E, Lenhardt R, Kurz A, et al. Nitrous oxide and risk of surgical wound infection: a randomised trial. Lancet. 2005;366(9491):1101-7.

19. Yang YF, Herbert L, Rüschen H, Cooling RJ. Nitrous oxide anaesthesia in the presence of intraocular gas can cause irreversible blindness. Br Med J. 2002;325:532-3.

20. Sharma B, Gupta R, Sehgal R, et al. ProSeal laryngeal mask airway cuff pressure changes with and without use of nitrous oxide during laparoscopic surgery. J Anaesth Clin Pharm. 2013;29(1):47-51.

21. Chen B-Z, Luo L-H, Jiang L, et al. The effect of nitrous oxide on intracuff pressure of the size 2 ProSeal Laryngeal Mask Airway. J Clin Anesth. 2011;23(3):214-7.

22. Akca O, Lenhardt R, Fleischmann E, et al. Nitrous oxide increases the incidence of bowel distension in patients undergoing elective colon resection. Acta Anaesthesiol Scand. 2004; 48(7):894-8.

23. Orhan-Sungur M, Apfel C, Akca O. Effects of nitrous oxide on intraoperative bowel distension. Curr Opin Anesthesiol. 2005;18(6):620-4.

24. Taylor E, Feinstein R, White PF, Soper N. Anesthesia for laparoscopic cholecystectomy. Is nitrous oxide contraindicated? Anesthesiology. 1992;76(4):541-3.
25. Brodsky JB, Lemmens HJM, Collins JS, et al. Nitrous oxide and laparoscopic bariatric surgery. Obes Surg. 2005;15(4):494-6.

26. - Apfel CC, Heidrich FM, Jukar-Rao S et al. Evidence-based analysis of risk factors for postoperative nausea and vomiting. Br J Anaesth 2012;109(5):742-53. The authors used multivariate logistic regression analyses to identify independent predictors of PONV, the most reliable of which were female gender, history of PONV or motion sickness, non-smoker, younger age, duration of anaesthesia with volatile anaesthetics, and postoperative opioids. Nitrous oxide was the weakest predictor of the anaesthesia-related risk factors, ranking behind use of volatiles, duration of anaesthesia and postoperative opioid use.

27. Mraovic B, Simurina T, Sonicki Z, et al. The dose-response of nitrous oxide in postoperative nausea in patients undergoing gynecologic laparoscopic surgery: a preliminary study. Anesth Analg. 2008;107(3):818-23.

28. Kapur PA. The big "little" problem (Editorial). Anesth Analg. 1991;73(3):243-5.

29. Tramèr $\mathrm{M}$, Moore $\mathrm{A}$, McQuay $\mathrm{H}$. Omitting nitrous oxide in general anaesthesia: meta-analysis of intraoperative awareness and postoperative emesis in randomized controlled trials. $\mathrm{Br} \mathbf{J}$ Anaesth. 1996;76(2):186-93.

30. Fernandez-Guisasola J, Gomez-Arnau JI, Cabrera Y, del Valle SG. Association between nitrous oxide and the incidence of postoperative nausea and vomiting in adults: a systematic review and meta-analysis. Anaesthesia. 2010;65(4):379-87.

31. • Peyton PJ, Wu CY. Nitrous oxide-related postoperative nausea and vomiting depends on duration of exposure. Anesthesiology 2014;120(5):1137-45. The authors conducted a meta-analysis of 29 studies involving 10,317 patients randomised to nitrous oxide or nitrous oxide-free anaesthesia. They evaluated the relationship between duration of anaesthesia and PONV in the first 24 hours after surgery. Duration of exposure dramatically increased this risk, with numbers needed to treat to prevent PONV by avoiding nitrous oxide of 128, 23, and 9 for exposures of less than 1 hour, 1-2 hours, and more than 2 hours, respectively. The effect of less than an hour of nitrous oxide was deemed to be clinically insignificant such that the risk of PONV should not preclude the use of nitrous oxide in ambulatory surgery.

32. Tramèr MR, Reynolds JM, Moore RA, McQuay HJ. Efficacy, dose-response, and safety of ondansetron in prevention of postoperative nausea and vomiting. A quantitative systematic review of randomized placebo-controlled trials. Anesthesiology. 1997;87(6):1277-89.

33. Ghoneim MM, Block RI, Haffarnan M, Mathews MJ. Awareness during anesthesia: risk factors, causes and sequelae: a review of reported cases in the literature. Anesth Analg. 2009;108(2):527-35.

34. Ishizawa Y. Special article: general anesthetic gases and the global environment. Anesth Analg. 2011;112(1):213-7.

35. Sherman SJ, Cullen BF. Nitrous oxide and the greenhouse effect (Editorial). Anesthesiology. 1988;68(5):816-7.

36. Boivin JF. Risk of spontaneous abortion in women occupationally exposed to anaesthetic gases: a meta-analysis. Occup Environ Med. 1997;54(8):541-8.

37. Nayebzadeh A. Exposure to exhaled nitrous oxide in hospitals post-anesthesia care units. Ind Health. 2007;45(2):334-7.

38. Health Services Advisory Committee. Anaesthetic agents: controlling exposure under COSHH. Suffolk: HSE Books; 1995.

39. National Institute for Occupational Safety and Health. Criteria for a recommended standard: occupational exposure to waste anesthetic gases and vapors. Cincinnati, Ohio: US Department of Health, Education and Welfare, Public Health Service, Center for Disease Control, 1977. 
40. - Chan MTV, Wan ACM, Gin T et al. Chronic postsurgical pain after nitrous oxide anesthesia. Pain 2011;152(11):2514-20. The authors conducted a follow-up study of all ENIGMA trial patients recruited in Hong Kong $(n=640)$. They recorded the severity of postsurgical pain of at least 3 months' duration using a structured telephone interview. Chronic postsurgical pain was common after major surgery, affecting $10.9 \%$ of patients overall. However, the intraoperative use of nitrous oxide reduced the risk by more than half. When nitrous oxide was avoided, $14.8 \%$ of patients experienced chronic pain and $12.9 \%$ had severe pain. Nitrous oxide use reduced chronic and severe pain to $7.0 \%$ and $5.6 \%$, respectively, with a NNT of 13 .

41. • Lee SY, Cheng SL, Ng SB, Lim SL. Single-breath vital capacity high concentration sevoflurane induction in children: with or without nitrous oxide? Br J Anaesth 2013;110(1):81-6. Eighty unpremedicated children aged 5-15 years old received a vital capacity induction of anaesthesia with $8 \%$ sevoflurane in either 6 litres/minute of $100 \%$ oxygen or $66 \%$ nitrous oxide in oxygen. Nitrous oxide reduced time to loss of the eyelash reflex from $63.5 \pm 16.1$ seconds to $53.6 \pm 16.1 \mathrm{~s}(p=0.01)$. Subsequent induction endpoints were similar between the groups but nitrous oxide also reduced excitatory movements $(p=0.007)$.

42. Ghatge S, Lee J, Smith I. Sevoflurane: an ideal agent for adult day-case anaesthesia? Acta Anaesthesiol Scand. 2003;47(8): 917-31.

43. Hall JE, Stewart JIM, Harmer M. Single-breath inhalation induction of sevoflurane anaesthesia with and without nitrous oxide: a feasibility study in adults and comparison with an intravenous bolus of propofol. Anaesthesia. 1997;52(5):410-5.

44. Nishiyama T. Is nitrous oxide useful for laryngeal mask airway insertion under 8\% sevoflurane? Masui. 2012;61(11):1221-5.

45. Ng J-M, Hwang N-C. Inhaling nitrous oxide reduces the induction dose requirements of propofol. Anesth Analg. 2000;90(5): 1213-6.

46. Ekbom K, Kalman S, Jakobsson J, Marcus C. Efficient intravenous access without distress: a double-blind randomized study of midazolam and nitrous oxide in children and adolescents. Arch Pediatr Adolesc Med. 2011;165(9):785-91.

47. Lin CY, Wang JS. Supramaximal second gas effect: a nonexistent phenomenon. Anesth Analg. 1993;77(4):870-1.

48. Sun X-G, Su F, Shi Y-Q, Lee C. The, "second gas effect" is not a valid concept. Anesth Analg. 1999;88(1):188-92.

49. Hendrickx JF, Carette R, Lemmens HJ, De Wolf AM. Large volume $\mathrm{N}_{2} \mathrm{O}$ uptake alone does not explain the second gas effect of $\mathrm{N}_{2} \mathrm{O}$ on sevoflurane during constant inspired ventilation. $\mathrm{Br} \mathrm{J}$ Anaesth. 2006;96(3):391-5.

50. Peyton PJ, Fortuin M, Robinson GJB, et al. The rate of alveolarcapillary uptake of sevoflurane and nitrous oxide following anaesthetic induction. Anaesthesia. 2008;63(4):358-63.

51. Peyton PJ, Stuart-Andrews C, Deo K, et al. Persisting concentrating and second gas effects on oxygenation during $\mathrm{N}_{2} \mathrm{O}$ anaesthesia. Anaesthesia. 2006;61(4):322-9.

52. Servin FS, Marchand-Maillet F, Desmonts J-M. Influence of analgesic supplementation on the target propofol concentrations for anaesthesia with 'Diprifusor' TCI. Anaesthesia. 1998;53 (Supplement s1):72-6.

53. Akhtar TM, Kerr WJ, Kenny GNC. Effect of nitrous oxide on post-operative nausea and vomiting during propofol anaesthesia for short surgical operations. Eur J Anaesthesiol. 1993;10: 337-41.

54. Arellano RJ, Pole ML, Rafuse SE, et al. Omission of nitrous oxide from a propofol-based anesthetic does not affect the recovery of women undergoing outpatient gynecologic surgery. Anesthesiology. 2000;93(2):332-9.
55. Handa-Tsutsui F, Kodaka M. Effect of nitrous oxide on propofol requirement during target-controlled infusion for oocyte retrieval. Int J Obstet Anesth. 2007;16(1):13-6.

56. Sengupta P, Plantevin OM. Nitrous oxide and day-case laparoscopy: effects on nausea, vomiting and return to normal activity. Br J Anaesth. 1988;60(5):570-3.

57. McKinney MS, Fee JPH. Cardiovascular effects of $50 \%$ nitrous oxide in older adult patients anaesthetized with isoflurane or halothane. Br J Anaesth. 1998;80(2):169-73.

58. Jakobsson J, Heidvall M, Davidson S. The sevoflurane-sparing effect of nitrous oxide: a clinical study. Acta Anaesthesiol Scand. 1999;43(4):411-4.

59. Servin FS, Billard V. Surrogate measures, do they really describe anaesthetic state? (Editorial). Br J Anaesth. 2014;115(5):787-90.

60. Barr G, Jakobsson JG, Öwall A, Anderson RE. Nitrous oxide does not alter bispectral index: study with nitrous oxide as sole agent and as an adjunct to i.v. anaesthesia. $\mathrm{Br} \mathrm{J}$ Anaesth. 1999;82(6):827-30.

61. Anderson RE, Jakobsson JG. Entropy of EEG during anaesthetic induction: a comparative study with propofol or nitrous oxide as sole agent. Br J Anaesth. 2004;92(2):167-70.

62. Anderson RE, Barr G, Jakobsson JG. Cerebral state index during anaesthetic induction: a comparative study with propofol or nitrous oxide. Acta Anaesthesiol Scand. 2005;49(6):750-3.

63. Liu N, LeGuen M, Boichut $\mathrm{N}$, et al. Nitrous oxide does not produce a clinically important sparing effect during closed-loop delivered propofol-remifentanil anaesthesia guided by the bispectral index: a randomized multicentre study. $\mathrm{Br} \mathrm{J}$ Anaesth. 2014;112(5):842-51.

64. Sukhani R, Lurie J, Jabamoni R. Propofol for ambulatory gynecological laparoscopy: does omission of nitrous oxide alter postoperative sequelae and recovery? Anesth Analg. 1994;78(5):831-5.

65. • Peyton PJ, Chao I, Weinberg L et al. Nitrous oxide diffusion and the second gas effect on emergence from anesthesia. Anesthesiology 2011;114(3):596-602. Twenty patients received sevoflurane in either air-oxygen or nitrous oxide- oxygen for maintenance of anaesthesia. Five minutes after the end of anaesthesia, arterial sevoflurane partial pressures were $39 \%$ higher in the air-oxygen group and correspondingly, times to eye opening (10.1 versus $8.7 \mathrm{~min})$ and extubation (13.2 versus $11.0 \mathrm{~min})$ were delayed $(p<0.04)$.

66. Brodsky JB, McKlveen RE, Zelcer J, Margary JJ. Diffusion hypoxia: a reappraisal using pulse oximetry. J Clin Monit. 1988;4(4):244-6.

67. Gift AG, Stanik J, Karpenick J, et al. Oxygen saturation in postoperative patients at low risk for hypoxemia: is oxygen therapy needed? Anesth Analg. 1995;80(2):368-72.

68. Mathews DM, Gaba V, Zaku B, Neuman GG. Can remifentanil replace nitrous oxide during anesthesia for ambulatory orthopedic surgery with desflurane and fentanyl? Anesth Analg. 2008; 106(1):101-8.

69. Peacock JE, Luntley JB, O'Connor B, et al. Remifentanil in combination with propofol for spontaneous ventilation anaesthesia. Br J Anaesth. 1998;80(4):509-11.

70. Coloma M, Chiu JW, White PF, Armbruster SC. The use of esmolol as an alternative to remifentanil during fast-track outpatient gynecologic laparoscopic surgery. Anesth Analg. 2001;92(2):352-7.

71. Guignard B, Bossard AE, Coste C, et al. Acute opioid tolerance: intraoperative remifentanil increases postoperative pain and morphine requirement. Anesthesiology. 2000;93(2):409-17.

72. Vinik HR, Kissin I. Rapid development of tolerance to analgesia during remifentanil infusion in humans. Anesth Analg. 1998; 86(6):1307-11. 
73. Lee LH, Irwin MG, Lui SK. Intraoperative remifentanil infusion does not increase postoperative opioid consumption compared with 70\% nitrous oxide. Anesthesiology. 2005;102(2):398-402.

74. - Echevarria G, Elgueta F, Fierro $\mathrm{C}$ et al. Nitrous oxide $\left(\mathrm{N}_{2} \mathrm{O}\right)$ reduces postoperative opioid-induced hyperalgesia after remifentanil-propofol anaesthesia in humans. $\mathrm{Br} \mathrm{J}$ Anaesth 2011;107(6):959-65. Fifty adult patients received infusions of propofol and remifentanil $(0.30 \mu \mathrm{g} / \mathrm{kg} / \mathrm{min})$ for elective septorhinoplasty. When anaesthesia was supplemented with $70 \%$ nitrous oxide, mechanical pain thresholds were found to show a significantly smaller decrease 12-18 h after surgery compared to patients receiving only propofol and remifentanil. The findings suggest that nitrous oxide significantly reduces postoperative hyperalgesia induced by remifentanil.

75. Sanders RD, Franks NP, Maze M. Xenon: no stranger to anaesthesia. Br J Anaesth. 2003;91(5):709-17.

76. Goto T, Saito H, Shinkai M, et al. Xenon provides faster emergence from anesthesia than does nitrous oxide-sevoflurane or nitrous oxide-isoflurane. Anesthesiology. 1997;86(6):1273-8.

77. Dingley J, Ivanova-Stoilova TM, Grundler S, Wall T. Xenon: recent developments. Anaesthesia. 1999;54(4):335-46. 